\title{
Fracture Mechanics Analysis of Reinforced DCB Sandwich Debond Specimen Loaded
} by Moments

Saseendran, Vishnu; Berggreen, Christian; Carlsson, Leif A.

Published in:

A I A A Journal

Link to article, DOI:

10.2514/1.J056039

Publication date:

2018

Document Version

Peer reviewed version

Link back to DTU Orbit

Citation (APA):

Saseendran, V., Berggreen, C., \& Carlsson, L. A. (2018). Fracture Mechanics Analysis of Reinforced DCB Sandwich Debond Specimen Loaded by Moments. A I A A Journal, 56(1), 413-422.

https://doi.org/10.2514/1.J056039

\section{General rights}

Copyright and moral rights for the publications made accessible in the public portal are retained by the authors and/or other copyright owners and it is a condition of accessing publications that users recognise and abide by the legal requirements associated with these rights.

- Users may download and print one copy of any publication from the public portal for the purpose of private study or research.

- You may not further distribute the material or use it for any profit-making activity or commercial gain

- You may freely distribute the URL identifying the publication in the public portal 


\title{
Energy Release Rate and Mode-Mixity of Face/Core Debond in Reinforced Sandwich Specimens Loaded by Moments
}

\author{
Vishnu Saseendran ${ }^{\S}$ and Christian Berggreen \\ Technical University of Denmark, Kgs Lyngby, DK-2800 \\ Email:vsas@mek.dtu.dk, cbe@mek.dtu.dk,web page: www.mek.dtu.dk \\ Leif A. Carlsson ${ }^{\ddagger}$ \\ Florida Atlantic University, Boca Raton Florida 33431, USA \\ Email: carlsson@fau.edu,web page: www.eng.fau.edu
}

\begin{abstract}
Analytical expressions for energy release rate and mode mixity phase angle are derived for a sandwich composite double cantilever beam fracture specimen with the face sheets reinforced by stiff plates. The sandwich beam is considered symmetric with identical top and bottom face sheets. Only pure moment loading is considered. J-integral coupled with laminate theory is employed to derive closed form expression for the energy release rate in terms of applied moments, geometry and material properties. A scalar quantity $\omega$ is obtained to express mode mixity phase angle. It is shown that $\omega$ is independent of applied loading conditions. The value of $\omega$ is found to be moderately influenced by reinforcement thicknesses.
\end{abstract}

\section{Nomenclature}

$\psi$ - mode-mixity phase angle

G - energy release rate

$\mathrm{J}$ - J- integral

a - pre-crack length

${ }^{\S}$ PhD Fellow, Department of Mechanical Engineering

${ }^{\ddagger}$ Professor, Department of Ocean and Mechanical Engineering 
$\Gamma$ - integration path for $J$ integral

$\varepsilon_{x}^{0}$ - laminate mid-plane strain

$\kappa_{X}$ - laminate mid-plane curvature

$\sigma_{i j}$ - stress tensor

$\mathrm{M}_{\mathrm{d}}$ - moment applied on debonded beam

$\mathrm{M}_{\mathrm{s}}$ - moment applied on substrate beam

$E_{f}-$ Young's modulus of face sheet

$\mathrm{E}_{\mathrm{c}}-$ Young's modulus of core

$E_{r}-$ Young's modulus of reinforcement layer

$h_{f}-$ thickness of face sheet

$\mathrm{h}_{\mathrm{c}}$ - thickness of core

$h_{r}-$ thickness of reinforcement layer

$\mathrm{K}$ - stress intensity factor

$\beta$ - Dundur's bimaterial parameter

$\varepsilon$ - oscillatory index

$\mathrm{e}_{\mathrm{d}}-$ neutral axis distance (debonded beam)

$\mathrm{e}_{\mathrm{s}}-$ neutral axis distance (substrate beam) 


\section{Introduction}

Face/core interface debonding is a serious failure mode that affects the performance of a sandwich structure. Debonds (face and core separation) can occur during liquid resin processing due to inadequate wetting of the face/core interface region which reduces the adhesive strength between face and core. Face/core debonds may also occur due to service loads such as wave slamming, impact and fatigue cycling. Debonds may propagate along the interface or kink into the core. The propensity of the crack to propagate is determined by the local stress state at the crack tip for a given loading condition. The stress intensity factors at the crack tip for a given loading condition can be expressed in terms of a mode-mixity phase angle $(\psi)$ which quantifies the ratio of shear to normal loading at the crack tip.

Determination of the interface fracture resistance is vital from a design perspective. There are various experimental methods developed to determine the interface fracture toughness such as the Cracked Sandwich Beam (CSB) [1], Double Cantilever Beam (DCB) [2], Tilted Sandwich Debond (TSD) specimen [3], the Three-Point Sandwich Beam (TPSB) [4] , Mixed-mode Bending (MMB) specimen [5] and Single Cantilever Beam (SCB) sandwich specimen [6]. Most of the devised experimental test methods were inspired by fracture test methods developed for laminate composites. For instance, the MMB test method developed for delamination testing [7], [8] was extended to sandwich composites [5] [9]. The SCB sandwich specimen is a simple test set-up for determining mode I fracture toughness of face/core interface [10]. However, appropriate sizing of the specimen must be undertaken to ensure that the face/core crack propagates along the interface [11] at mode I loading. Efforts are underway to implement the SCB sandwich specimen as a standard test method for mode I fracture toughness characterization [12].

Due to the high elastic mismatch across the interface in sandwich composites, the face/core crack is inherently mixed mode. A full characterization of the face/core interface inevitably requires testing over a wide array of mode-mixity phase angles. Therefore, it is desirable to control the mode-mixity during the test. A relatively recently developed test method for delamination testing is the Double Cantilever Beam loaded with Uneven Bending Moments (DCB-UBM) developed by Sørensen et al. [13]. This method was recently extended to sandwich composites by Østergaard et al. [14] and Lundsgaard- 
Larsen et al. [15], and is schematically illustrated in Fig 1. In this method, it is possible to perform a fracture test at a desired mode-mixity by controlling the moments $M_{1}$ and $M_{2}$ applied to the specimen end.

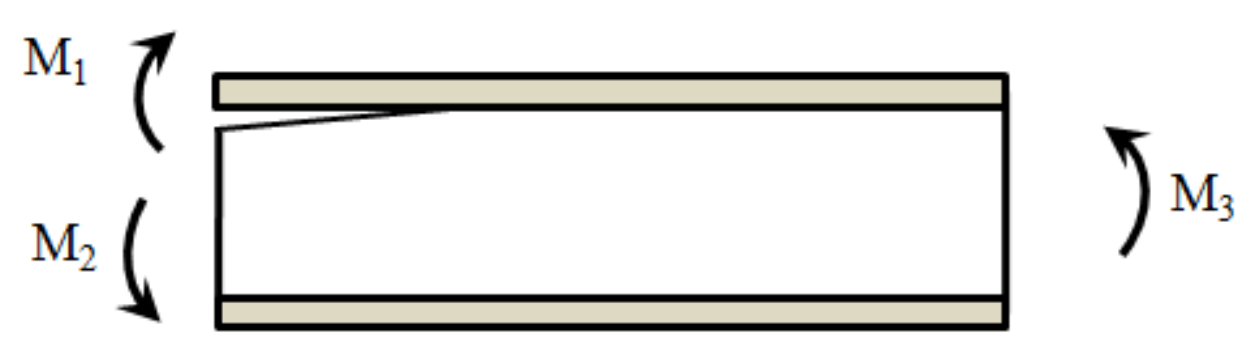

Figure 1. DCB-UBM specimen loaded with edge moments

Reference is made here to the crack element approach by Suo and Hutchinson [16] who developed a fracture mechanics analysis approach for a bi-layer element and Kardomateas et al. [17] who extended this procedure to a cracked sandwich element. These authors considered only in-plane (axial) forces and moment couples acting on the edge of the specimen. An analytical expression for the energy release rate, $G$, was obtained through the $J$-integral. The mode decomposition was performed using the stress intensity factors $K_{I}$ and $K_{I I}$, derived analytically except for a single scalar parameter $\omega$, which was extracted from the numerical solution of one loading combination.

Sandwich panels with thin facesheets (in the range of $0.5 \mathrm{~mm}$ ) are not uncommon, especially in the aircraft industry. Fracture characterization of such sandwich composites possess many problems such as load application to the debonded face sheets which, if thin, will undergo large nonlinear deflections and rotations. A method to reduce displacements is to reinforce one or both faces with stiff layers named doublers. This method was adopted by Lundsgaard-Larsen et al. [15], who bonded stiff steel plates to both facesheets to reduce the rotation. In this paper, expressions for the energy release rate and mode-mixity phase angle are derived for a reinforced DCB-UBM fracture specimen loaded by pure edge moments. The mode-mixity phase angle $(\psi)$ quantifies the ratio between mode II and mode I stress intensity factors.

\section{Analysis of Sandwich Fracture Specimen}

The sandwich specimen considered here (see Fig. 2) consists of five layers, two composite face sheet laminates labeled 1 and 2, the core, and two reinforcing plates of thickness $h_{r}$, bonded to each of the face sheets. Typically, the face sheets are 
composed of multi-directional laminates with plies arranged in a symmetric and balanced way. Analysis of such a sandwich element is simplified by homogenizing the laminate into a specially orthotropic composite layer of the same thickness as the laminate, and stiffness $E_{1}, E_{2}, v_{12}, v_{21}$ and $G_{12}$. The approach presented here, however, assumes all layers are isotropic with Young's modulus $E$ and Poisson's ratio $v$. Transformation of orthotropic elastic constant of the laminate face sheet into isotropic constant is discussed in Appendix B.

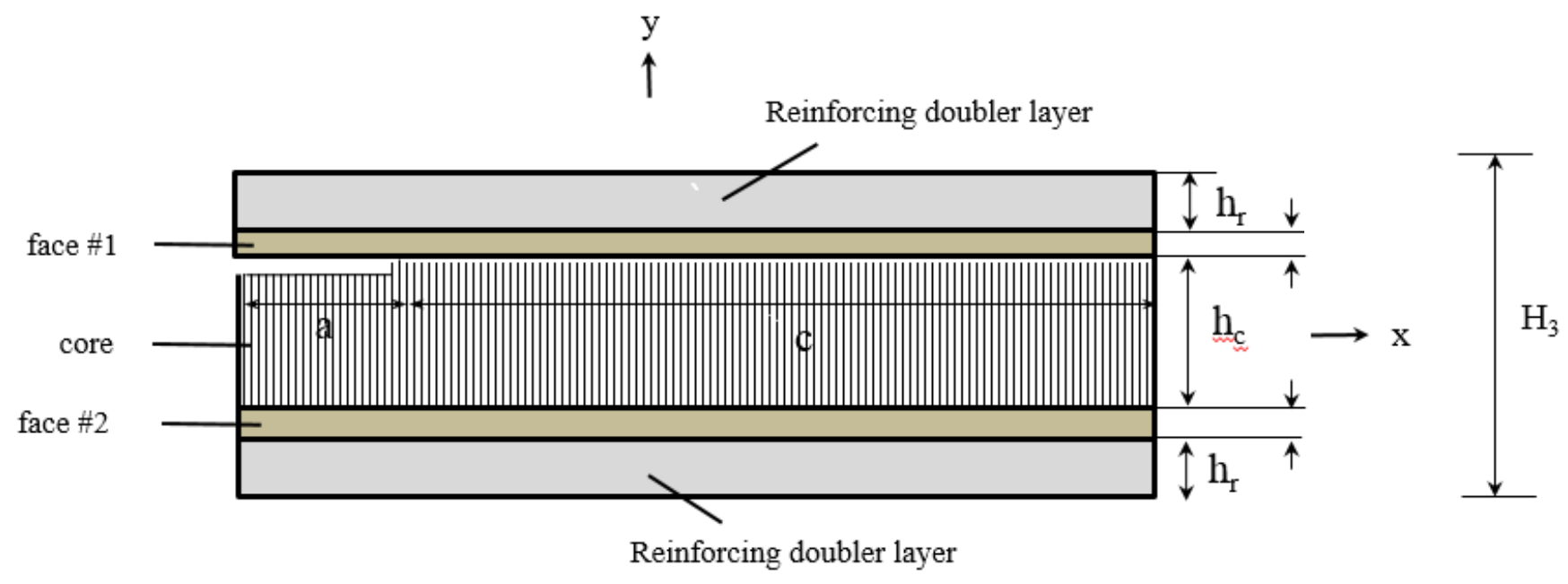

Figure 2. Sandwich beam element with reinforcing doubler layers of thickness $h_{r}$

Figure 3 shows the superposition scheme used for the analysis of DCB-UBM specimen. The original configuration is shown in Fig. 3a. By adding the un-cracked configuration subject to pure moments per unit width, $M_{3}$, as shown in Fig. 3b, the force and moment configuration shown in Fig. 3c is obtained. As indicated in Fig. 3c, beam \#1, referred to as the debonded beam, consists of the top face sheet and reinforcement layer (thickness, $H_{1}=h_{r}+h_{f}$ ) and beam \#2 referred as the substrate part consists of the layers beneath the pre-crack i.e. core, bottom face sheet and bottom reinforcement layer (thickness, $H_{2}=h_{c}+$ $h_{f}+h_{r}$ ). The intact portion right of the crack front comprising of both face sheets, reinforcement layers and the core is referred to as the base part (thickness, $H_{3}=2 h_{r}+2 h_{f}+h_{c}$ ). Hence, the two systems will have same energy-release rate and stress intensity factors. This analysis follows the principal approach performed by Suo and Hutchinson for a bi-material interface [16]. The DCB-UBM specimen is loaded by pure moments per unit width, $M_{1}$ and $M_{2}$, applied to the left edge as shown in Fig. 1. Hence, there are no axial in-plane forces or transverse shear force acting on the specimen. In some cases, axial loads are acting on the sections. Suo and Hutchinson [18] considered axial loads $\mathrm{P}_{1}, \mathrm{P}_{2}$ and $\mathrm{P}_{3}$ per unit width. $\mathrm{P}_{1}$ and $\mathrm{P}_{2}$ act on the 
left edge and $\mathrm{P}_{3}$ acts on the right edge. The influence of these forces on the crack loading is included in their analysis, and it is possible to consider such loads also in the present analysis. For the specific test specimen considered here (DCB-UBM), however, there is no axial force present, and hence is not considered in our analysis.

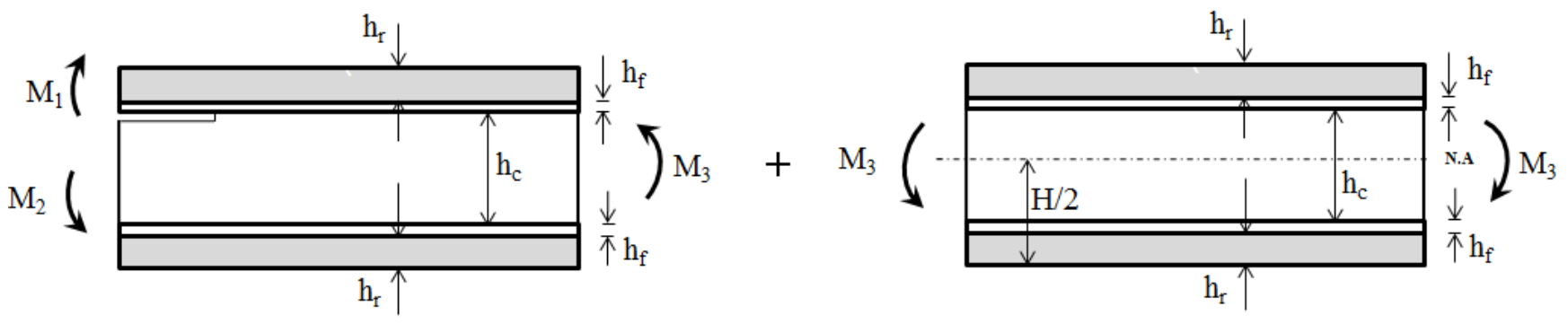

(a)
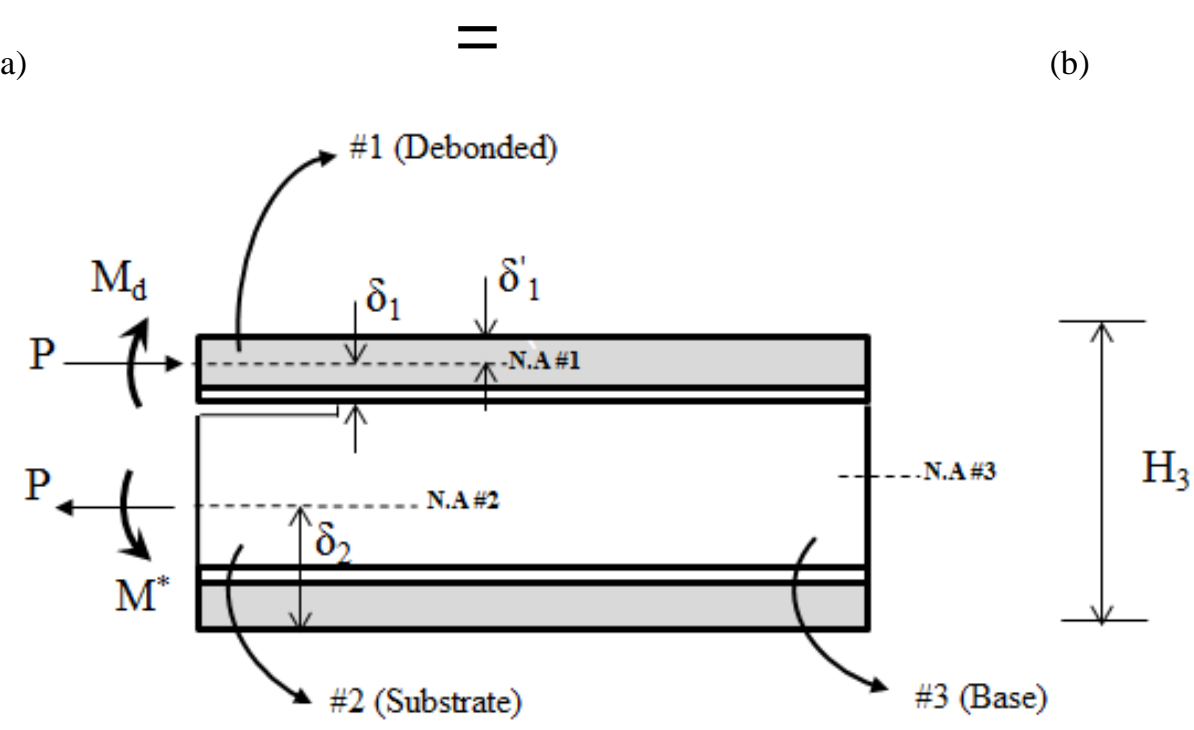

(c)

Figure 3. Superposition scheme of sandwich geometry

The moment acting on the debonded arm, $M_{d}$, and axial force, $P$ can be expressed in terms of $M_{3}$ as:

$$
\begin{aligned}
& P=-c_{2} M_{3} \\
& M_{d}=M_{1}-c_{3} M_{3}
\end{aligned}
$$

where expressions for $c_{2}$ and $c_{3}$ are obtained from stress analysis of each beam provided later. Notice that the three original loading parameters are reduced to two independent variables, $P$ and $M_{d}$. From equilibrium,

$$
M^{*}=M_{d}+P \Delta_{1}
$$


where

$$
\Delta_{1}=H_{3}-\delta_{1}^{\prime}-\delta_{2}
$$

and

$$
\delta_{1}^{\prime}=H_{1}-\delta_{1}
$$

The distribution of stress in each sub-beam can be determined from laminate beam theory [19] where each part of the sandwich beam is considered as multi-layered beam (see Fig. 3). The thickness of the debonded beam \#1 is $H_{1}=h_{f}+h_{r}$ and of the substrate beam \#2 is $H_{2}=h_{c}+h_{f}+h_{r}$. The force and moment (per unit width) are given by [19]:

$$
\begin{aligned}
& N_{X}=A \varepsilon_{X}^{0}+B \kappa_{X} \\
& M_{X}=B \varepsilon_{X}^{0}+D \kappa_{X}
\end{aligned}
$$

where $N_{x}$ and $M_{x}$ are the force and moment resultants, and $\varepsilon_{x}^{0}$ and $\kappa_{x}$ are the mid-plane strain and curvature. The extension, coupling and bending stiffnesses (A, B and D) are defined as:

$$
\begin{aligned}
& A=\sum_{k=1}^{n} \bar{E}_{k}\left(\mathrm{y}_{k}-\mathrm{y}_{k-1}\right) \\
& B=\frac{1}{2} \sum_{k=1}^{n} \bar{E}_{k}\left(\mathrm{y}_{k}^{2}-\mathrm{y}_{k-1}^{2}\right) \\
& D=\frac{1}{3} \sum_{k=1}^{n} \bar{E}_{k}\left(\mathrm{y}_{k}^{3}-\mathrm{y}_{k-1}^{3}\right)
\end{aligned}
$$

where the $y$-axis is referenced to the geometric mid-plane $(y=0)$. $k$ is the layer index $k=1,2 \ldots \mathrm{n}$, where $n$ is the number of layers. $y_{k}$ is the $y$-coordinate of the interface between layers $k$ and $k+1$. Note that $y_{0}=-h / 2$ where $h$ is the total laminate thickness. $\bar{E}_{k}$ is the elastic modulus in the $x$ - direction for ply $k$. For plane strain, $\bar{E}_{k}=E_{k} /\left(1-v_{k}^{2}\right)$ while for plane stress, $\bar{E}_{k}=E_{k}$. An example of the layer coordinates, $\left(y_{k}\right)$ for the intact part of the specimen (\#3 in Fig. 3c) is shown in Fig. 4. 


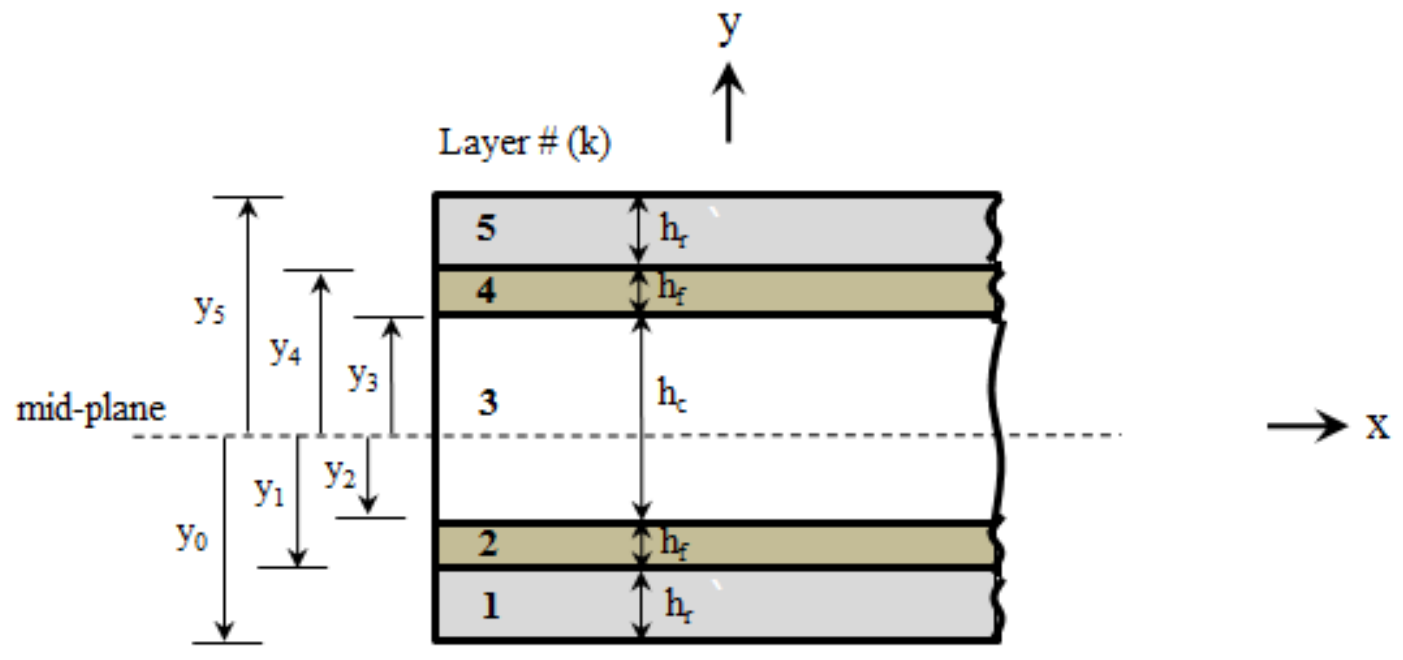

Figure 4. Layer definition for the intact part (\#3) of the sandwich specimen

The stress in each layer is:

$$
\left(\sigma_{X}\right)_{k}=\bar{E}_{k} \varepsilon_{X}
$$

where the strain is given by:

$$
\varepsilon_{X}=\varepsilon_{x}^{0}+\kappa_{X} \mathrm{y}
$$

Consider first the configuration shown in Fig. 3b. Figure 4 shows the layer coordinates. For the pure bending case, substituting $\left(N_{x}=0\right)$ in Eq. (4), provides the mid-plane strain, and the y-coordinate of the neutral axis:

$$
\begin{array}{r}
\varepsilon_{x}^{0}=-\frac{B \kappa_{x}}{A} \\
y_{N A}=\frac{B}{A}
\end{array}
$$

For simplicity, the sandwich beam is assumed to be symmetric $(B=0)$. For this case, Eq. (4b) yields, $M_{x}=D \kappa_{x}$. Rearranging and substituting for $\varepsilon_{x}^{0}=0$ in Eq. (7) gives,

$$
\varepsilon_{X}=\kappa_{X} y=\frac{M_{3}}{D} y
$$


Substituting $\varepsilon_{x}$ in Eq. (6) to obtain stress: $\left(\sigma_{x}\right)_{k}=\bar{E}_{k} \frac{M_{3}}{D} y$. The force, $P$, acting on debonded part (beam \#1), Fig. 3, is obtained by integrating the stress $\left(\sigma_{x}\right)_{k}$ over the cross section as:

$$
P=-\int_{h_{C} / 2}^{H_{3} / 2} \sigma_{X} d y=-c_{2} M_{3}
$$

Integration yields,

$$
c_{2}=\frac{\bar{E}_{f}\left(y_{4}^{2}-y_{3}^{2}\right)+\bar{E}_{r}\left(y_{5}^{2}-y_{4}^{2}\right)}{2 D}
$$

where the ply coordinates are illustrated in Fig. 4 . The moment $M_{d}$, Fig. 3, acting on beam \#1 (debonded) is given by:

$$
\begin{gathered}
M_{d}=M_{1}-\int_{h_{c} / 2}^{H_{3} / 2} \sigma_{x}\left(y-\left(\frac{h_{C}}{2}+\delta_{1}\right)\right) d y \\
M_{d}=M_{1}-c_{3} M_{3}
\end{gathered}
$$

where

$$
\begin{aligned}
c_{3}= & \frac{\bar{E}_{f}}{D}\left[\frac{1}{3}\left(\left(\frac{h_{C}}{2}+h_{f}\right)^{3}-\frac{h_{C}^{3}}{8}\right)-\frac{\left(\frac{h_{C}}{2}+\delta_{1}\right)}{2}\left(\left(\frac{h_{C}}{2}+h_{f}\right)^{2}-\frac{h_{C}^{2}}{4}\right)\right] \\
& \left.+\frac{\bar{E}_{r}}{D}\left[\frac{1}{3}\left(\frac{H_{3}^{3}}{8}-\left(\frac{h_{C}}{2}+h_{f}\right)^{3}\right)-\frac{\left(\frac{h_{C}}{2}+\delta_{1}\right.}{2}\right)\left(\frac{H_{3}^{2}}{4}-\left(\frac{h_{C}}{2}+h_{f}\right)^{2}\right)\right]
\end{aligned}
$$

\section{J-integral calculation}

The current analysis is carried out in the ambit of Linear Elastic Fracture Mechanics (LEFM) regime. In order to obtain the energy release rate for a pre-cracked sandwich element reinforced with stiff doubler layers, the $J$-integral approach is chosen. 


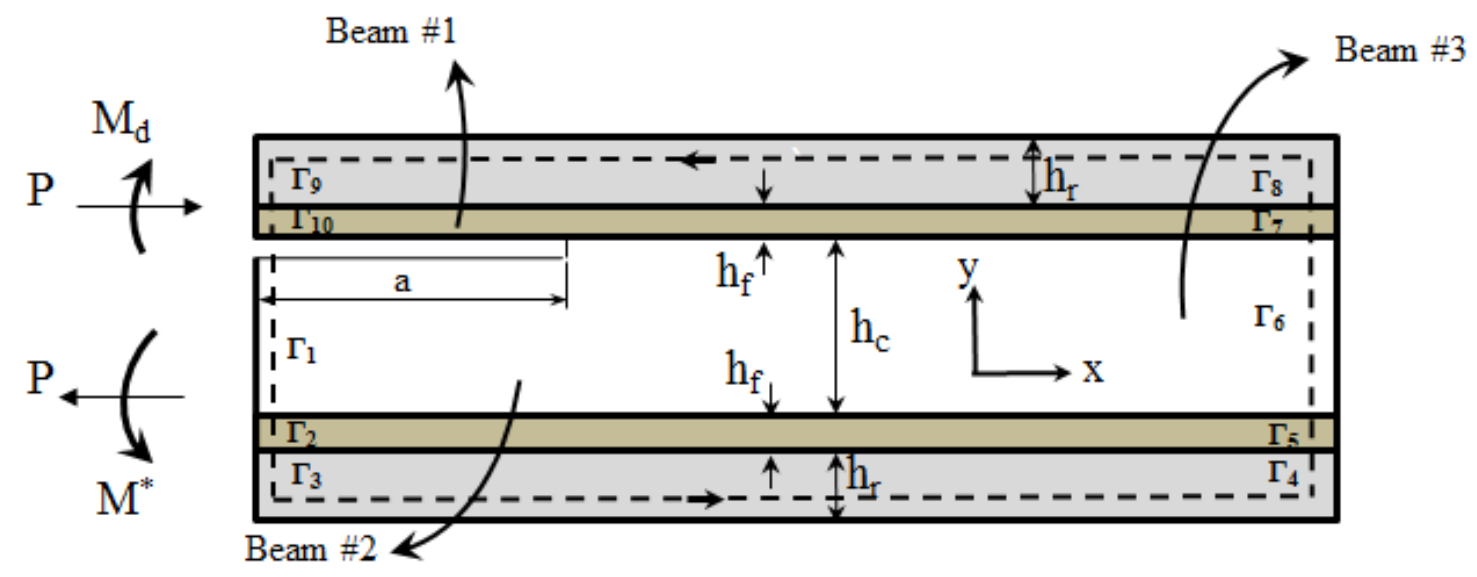

Figure 5. J-integral path in reinforced sandwich beam

J-integral was calculated for the closed path shown in Fig. 5 using the general expression [20] :

$$
J=\int_{\Gamma} W d y-\sigma_{i j} n_{j} \cdot \frac{\partial u_{i}}{\partial x} d S
$$

where $\sigma_{i j}$ is the stress tensor, $d S$ is a length increment along the closed path $\Gamma, n_{j}$ is an outward normal vector to the closed contour and $u_{i}$ is the displacement vector. $W$ is the strain energy density, $W=\frac{1}{2} \sigma_{X} \varepsilon_{X}$. The $J$-integral is non-zero only along the vertical paths near the left edge marked $\Gamma_{1}-\Gamma_{3}$ and $\Gamma_{9}-\Gamma_{10}$. For the horizontal paths $d y=0$ and, the normal vector is directed along the $y$-axis: $\sigma_{i j} n_{j}=0$, making no contribution to $J$. Furthermore, the vertical paths $\left(\Gamma_{4}-\Gamma_{8}\right)$ along right edge do not contribute to $J$ as no load acts on that edge (see Fig. 5). The $J$-integral is evaluated for all layers and summed up:

$$
J=\sum_{p=1 \Gamma}^{10} \int_{\Gamma}-\frac{1}{2} \bar{E}_{p} \sigma_{x}^{2} d y
$$

According to Eq. (15) J-integral is calculated from the stress $\sigma_{x}$ which is due to the acting moments and forces (see Fig. 5).

The total energy release rate then becomes:

$$
J=G=J_{\text {Debonded }}+J_{\text {Substrate }}=J_{1}+J_{2}+J_{3}+J_{9}+J_{10}
$$

$J_{1}$ through $J_{3}$ and $J_{9}-J_{10}$ are calculated from the stress in each layer. A detailed derivation of the $J$ integral is provided in Appendix A, which yields, 


$$
\begin{aligned}
G & =P^{2}\left(\frac{L_{1}}{(\bar{E} h)_{d}^{2}}+\frac{V_{1}}{(\bar{E} h)_{s}^{2}}+\frac{V_{2} \Delta_{1}^{2}}{H_{s}^{2}}-\frac{V_{3} \Delta_{1}}{(\bar{E} h)_{s} H_{s}}\right)+M_{d}^{2}\left(\frac{L_{2}}{H_{d}^{2}}+\frac{V_{2}}{H_{s}^{2}}\right)+ \\
& M_{d} P\left(\frac{2 V_{2} \Delta_{1}}{H_{S}^{2}}-\frac{L_{3}}{(\bar{E} h)_{d} H_{d}}-\frac{V_{3}}{(\bar{E} h)_{s} H_{s}}\right)
\end{aligned}
$$

This equation is derived in Appendix A. The above expression for $G$ is re-arranged to obtain a quadratic form in $P$ and $M_{d}$ similar to [17] as follows:

$$
J=G=a_{1} P^{2}+a_{2} M_{d}^{2}-a_{3} P M_{d}
$$

where

$$
\begin{gathered}
a_{1}=\frac{L_{1}}{(\bar{E} h)_{d}^{2}}+\frac{V_{1}}{(\bar{E} h)_{s}^{2}}+\frac{\Delta^{2} V_{2}}{H_{S}^{2}}+\frac{\Delta V_{3}}{(\bar{E} h)_{S} H_{S}} \\
a_{2}=\frac{L_{2}}{H_{d}^{2}}+\frac{V_{2}}{H_{S}^{2}} \\
a_{3}=-\frac{2 \Delta V_{2}}{H_{S}^{2}}-\frac{L_{3}}{(\bar{E} h)_{d} H_{d}}-\frac{V_{3}}{(\bar{E} h)_{S} H_{S}}
\end{gathered}
$$

\section{Mode-Mixity expression}

The energy release rate may be expressed in terms of a complex stress intensity factor $\left(K=K_{1}+i K_{2}\right)[13,14]$ as:

$$
G=B|\mathrm{~K}|^{2}
$$

where $i=\sqrt{-1}$ and

$$
B=\frac{G_{C}\left(\kappa_{f}+1\right)+G_{f}\left(\kappa_{C}+1\right)}{16 G_{f} G_{C} \cosh ^{2} \pi \varepsilon}
$$

where $\varepsilon$, the oscillatory index is expressed as: 


$$
\varepsilon=\frac{1}{2 \pi} \ln \left(\frac{1-\beta}{1+\beta}\right)
$$

The Dundur's parameter $\beta$, is given by

$$
\beta=\frac{G_{f}\left(\kappa_{C}-1\right)-G_{C}\left(\kappa_{f}-1\right)}{G_{C}\left(\kappa_{C}+1\right)+G_{C}\left(\kappa_{f}+1\right)}
$$

$G_{f}$ and $G_{c}$ are the shear moduli of the face and core. $\kappa_{m}=\left(3-4 v_{m}\right) /\left(1+v_{m}\right)$ for plane strain and $\kappa_{m}=3-4 v_{m}$ for plane stress conditions. $v_{\mathrm{m}}$ is the Poisson's ratio, $m=1$ and 2 for upper face sheet and core respectively. Substituting energy release rate, $G$ from Eq. (18) in (20) yields:

$$
|\mathrm{K}|^{2}=\frac{1}{B}\left(a_{1} P^{2}+a_{2} M_{d}^{2}-a_{3} P M_{d}\right)
$$

There are two possible roots for $K$ in Eq. (24). The roots for $K$ include both real and imaginary parts. Kardomateas et al. [17] found the roots of a similar equation following the approach of Thouless et al. [23] and Hutchinson et al. [16]. Therefore, exploiting similar arguments the complex stress intensity factor $K$ can be written as:

$$
\mathrm{K}=\frac{1}{\sqrt{B}}\left(-a P \sqrt{a_{1}}+b M_{d} \sqrt{a_{2}}\right) h_{f}^{-i \varepsilon}
$$

It should be noted that Eq. (24) is of same form as in [17]. For the first root, the complex numbers $a$ and $b$ are defined [18]:

$$
a=e^{i \varepsilon} \quad b=-i e^{i(\omega+\gamma)}
$$

where

$$
\sin \gamma=\frac{a_{3}}{2 \sqrt{a_{1} a_{2}}}
$$

It is required that $a$ and $b$ are independent of loading for the derivation of closed form solution of mode-mixity. Thus, by selecting the first root, the parameter $\omega$ in Eq. (26) becomes dependent only on geometry and material properties of the reinforced sandwich specimen but not on loading. Substituting $a$ and $b$ in Eq. (25) leads to: 


$$
\mathrm{K}=K_{1}+i K_{2}=\frac{1}{\sqrt{B}}\left(-P \sqrt{a_{1}}-i e^{i \gamma_{M}} M_{a_{2}}\right) h_{f}^{-i \varepsilon} e^{i \omega}
$$

The definition of the mode-mixity phase angle follows Hutchinson and Suo [18] for a bimaterial interface crack. The mode mixity phase angle $\psi$ is defined as:

$$
\psi=\tan ^{-1}\left(\frac{\operatorname{Im}\left[\mathrm{K} h_{f}^{i \varepsilon}\right]}{\operatorname{Re}\left[\mathrm{K} h_{f}^{i \varepsilon}\right]}\right)
$$

where the real and imaginary parts of the arguments are [23]:

$$
\begin{array}{r}
\operatorname{Re}\left[\mathrm{K} h_{f}^{i \varepsilon}\right]=\frac{1}{\sqrt{B}}\left[-P \sqrt{a_{1}} \cos \omega+M_{d} \sqrt{a_{2}} \sin (\omega+\gamma)\right] \\
\operatorname{Im}\left[\mathrm{K} h_{f}^{i \varepsilon}\right]=\frac{1}{\sqrt{B}}\left[-P \sqrt{a_{1}} \sin \omega-M_{d} \sqrt{a_{2}} \cos (\omega+\gamma)\right]
\end{array}
$$

Note that the near tip oscillation is suppressed by this definition of $\psi$, and that $\operatorname{Re}\left[\mathrm{K} h_{f}^{i \varepsilon}\right]=|K| \cos \psi$ and $\operatorname{Im}\left[\mathrm{K} h_{f}^{i \varepsilon}\right]=|K| \sin \psi$. An expression for the phase angle $\psi$ can be obtained from Eqs.(29) and (30):

$$
\tan \psi=\frac{\lambda \sin \omega-\cos (\omega+\gamma)}{\lambda \cos \omega+\sin (\omega+\gamma)}
$$

where

$$
\lambda=-\frac{P}{M_{d}} \sqrt{\frac{a_{1}}{a_{2}}}
$$

The parameter $\lambda$ incorporates the influence of stiffened face sheet through $a_{1}$ and $a_{2}$. The parameter $\omega$ can be expressed in terms of the phase angle as:

$$
\omega=\tan ^{-1}\left[\frac{\cos \gamma+(\lambda+\sin \gamma) \tan \psi}{\lambda+\sin \gamma-\cos \gamma \tan \psi}\right]
$$




\section{Calculation of $\psi$ and $\omega$}

Finite element analysis (FEA) of the DCB-UBM specimen combined with a method to extract the stress intensity factors called the Crack Surface Displacement Extrapolation (CSDE) method [24] is employed here to calculate $\omega$ and $\psi$. Twodimensional plane strain models of sandwich specimens were made in ANSYS ${ }^{\circledR}$ [25], comprising iso-parametric 4-node (PLANE 42) and 8-node (PLANE 82) elements. A highly discretized mesh was used near crack tip (see Fig. 6). The face sheets, core and reinforcement layers are considered linear elastic and isotropic. The PLANE 42 elements were used at the crack tip with a minimum element size of $0.005 \mathrm{~mm}$. These elements were used to capture the large strain gradients encountered at the crack region. The mode-mixity phase angle $(\psi)$ is extracted from the near-tip crack flank displacements in the following form:

$$
\psi=\tan ^{-1}\left(\frac{\delta_{X}}{\delta_{y}}\right)-\varepsilon \ln \left(\frac{x}{h}\right)+\tan ^{-1}(2 \varepsilon)
$$

where $x$ is distance behind the crack tip, $\varepsilon$ is the oscillatory index (Eq. 22) and $h$ is a characteristic length, which is taken as the face sheet thickness, $h=h_{f}$. The CSDE method is implemented as a subroutine in the commercial FE-package ANSYS ${ }^{\circledR}$ and employs crack flank opening and sliding displacements $\left(\delta_{\mathrm{y}}\right.$ and $\left.\delta_{\mathrm{x}}\right)$ over a region very close to behind the crack tip. The energy release rate is given by [24]:

$$
G_{C S D E}=\frac{\pi G_{m}\left(1+4 \varepsilon^{2}\right)}{2 x\left(k_{m}+1\right)}\left(\delta_{x}^{2}+\delta_{y}^{2}\right)
$$

where $k_{m}=\left(3-4 v_{m}\right)$ for plane strain and $k_{m}=\left(3-4 v_{m}\right) /\left(1+v_{m}\right)$ for plane stress, $v_{m}$ is Poisson's ratio. $m=1$ and 2 for face and core. $G_{1}$ and $G_{2}$ are the shear moduli of the face and core materials respectively.

FEA is performed on both un-reinforced and reinforced DCB-UBM sandwich specimens. FEA results for un-reinforced specimens are compared to analytical expressions derived here for the energy release rate $G_{\text {anal }}$ (Eq. (17)) and expressions available in literature for un-reinforced specimens [17]. The material properties of face and core employed in the analysis are provided in Table 1. In the second part of analysis, a reinforced sandwich DCB-UBM specimen with a soft core (PVC H45 foam) is considered. 


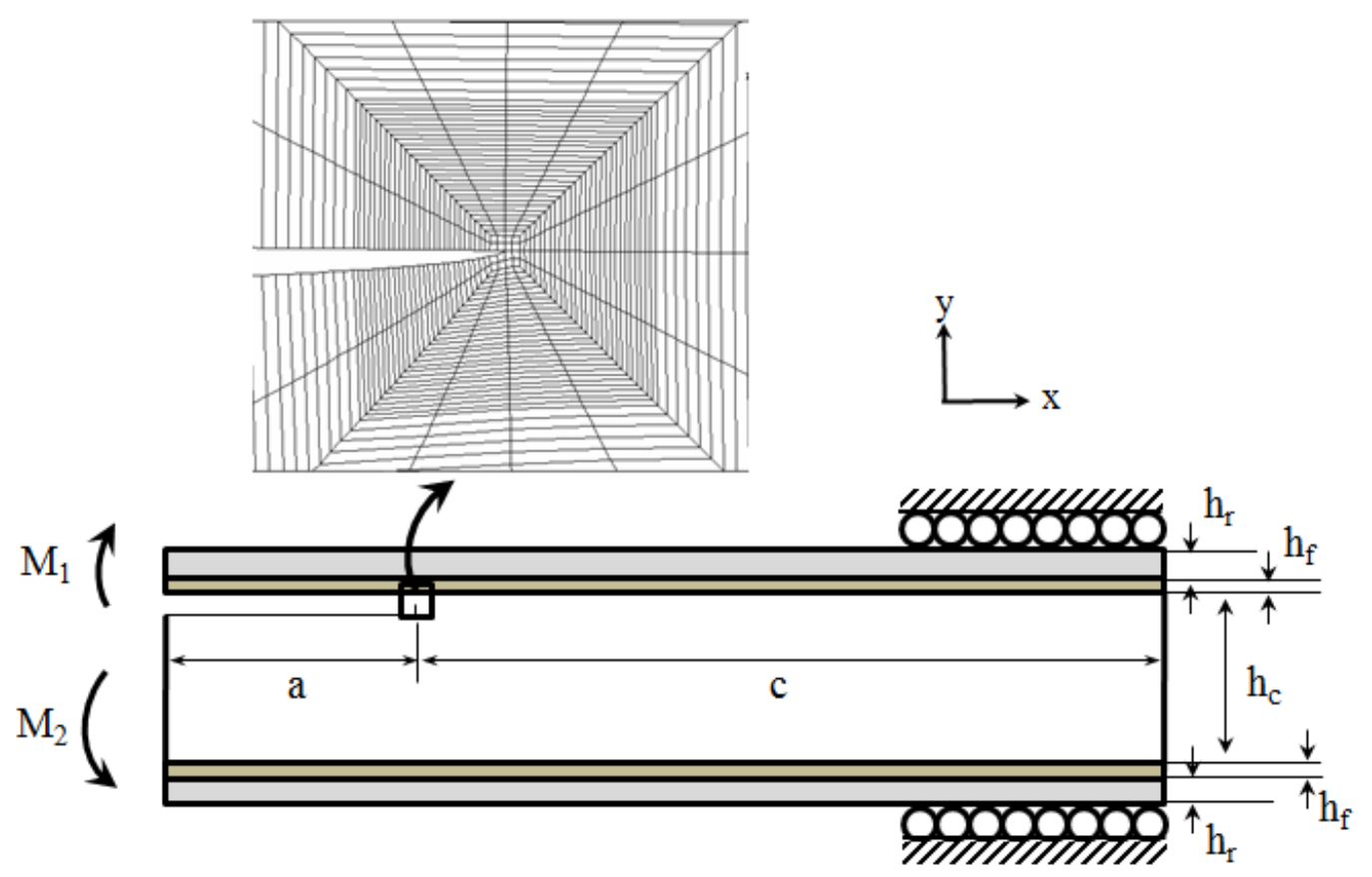

Figure 6. FE-model of reinforced DCB-UBM sandwich specimen

Table 1. Material properties of face sheet and core [9]

\begin{tabular}{|c|c|c|c|c|}
\hline Core & H45 & H100 & H250 & $\begin{array}{c}\text { Aluminum foam } \\
\text { core }\end{array}$ \\
\hline Young's modulus, $E_{c}[\mathrm{MPa}]$ & 50 & 130 & 300 & 7000 \\
\hline Shear modulus, $G_{c}[\mathrm{MPa}]$ & 15 & 35 & 104 & 2,630 \\
\hline Poisson's ratio, $v_{c}$ & 0.32 & 0.32 & 0.32 & 0.32 \\
\hline Face sheet & \multicolumn{2}{|c|}{ Aluminum face } & \multicolumn{2}{|c|}{$\begin{array}{c}\text { E-glass fibre - } \\
\text { DBLT-850(0/45/90/-45) }\end{array}$} \\
\hline Young's modulus, $E_{f}[\mathrm{GPa}]$ & \multicolumn{2}{|c|}{70} & \multicolumn{2}{|c|}{16.4} \\
\hline sShear modulus, $G_{f}[\mathrm{GPa}]$ & \multicolumn{2}{|c|}{26.9} & \multicolumn{2}{|c|}{5.8} \\
\hline Poisson's ratio, $v_{f}$ & \multicolumn{2}{|c|}{0.30} & \multicolumn{2}{|c|}{0.306} \\
\hline
\end{tabular}




\section{V. (A). Unreinforced DCB-UBM Sandwich Specimen}

Two unreinforced sandwich configurations comprising of $2 \mathrm{~mm}$ thick aluminum face sheets, and a $20 \mathrm{~mm}$ thick soft core (PVC H100) and a stiff core (aluminum foam) were chosen to benchmark the analytical expressions. For both cases, refer to Table 1 for material properties. A crack length, $a=200 \mathrm{~mm}$ was used with a sufficiently long specimen to reduce the edge effects ( $c=300 \mathrm{~mm}$ ). The mode-mixity of a DCB-UBM specimen is changed by altering the ratio of the moments $M_{1}$ and $M_{2}$ applied to the edge (moment ratio $M R=M_{1} / M_{2}$ ) (Fig. 1). The MR values, thicknesses and material properties were taken from [17] in-order to compare the energy release rate and mode-mixity results to the results obtained herein (Eqs. 17 and 29). Such a direct comparison is made by making the reinforcement layer modulus equal to that of the face sheets and making the sum of each face sheet thickness and reinforcement thickness equal to the face thickness analyzed in [17]. The results are examined over a range of moment ratios (MR).

Tables 2 and 3 list energy release rate results for a large range of moment ratios (MR). Close agreement between numerical $\left(G_{C S D E}\right)$ and analytical $\left(G_{\text {anal }}\right.$ ) results is noted. The current results for $G$ also agree with [15] and [17]. Note that results from [17] are compared here with moment loading only. It is furthermore noted that the parameter $\omega$ remains relatively constant for each case. For the PVC core sandwich, the largest deviation of $\omega$ from the average value is $0.5 \%$ whereas the deviation for the stiffer aluminum foam core is below 2.1\%. It should be further pointed out that the phase angle results presented in Tables 2 and 3 compare well with those published earlier in [17].

Table 2. G, $\psi$ and $\omega$ results for unreinforced DCB-UBM sandwich specimen with PVC H100 core

\begin{tabular}{l|lllll}
\hline Moment Ratio, $M R$ & -0.125 & -0.25 & -1.0 & 0.25 & 0.125 \\
$M_{1}[\mathrm{Nmm}]$ & 75.6 & 129.6 & 196.1 & 118.6 & 71.1 \\
$M_{2}[\mathrm{Nmm}]$ & -604.8 & -518.4 & -196.1 & 474.4 & 568.8 \\
$G_{\text {anal }}[\mathrm{N} / \mathrm{mm}]$ & 0.4238 & 0.4349 & 0.4140 & 0.3642 & 0.3749 \\
$G_{\text {CSDE }}[\mathrm{N} / \mathrm{mm}]$ & 0.4076 & 0.4214 & 0.4107 & 0.3553 & 0.3626 \\
$G[\mathrm{~N} / \mathrm{mm}][17]$ & 0.4239 & 0.4350 & 0.4140 & 0.3613 & 0.3727 \\
$\psi[\mathrm{deg}]$ & 52.60 & 35.60 & 1.11 & -62.87 & -85.40 \\
$\omega[\mathrm{deg}]$ & 74.09 & 73.66 & 73.34 & 73.74 & 73.54
\end{tabular}


Table 3. $G, \psi$ and $\omega$ for unreinforced DCB-UBM sandwich specimen with Aluminum foam core

\begin{tabular}{l|lllll}
\hline Moment Ratio, $M R$ & -0.002 & -0.02 & -0.0625 & -1.0 & 0.0625 \\
$M_{1}[\mathrm{Nmm}]$ & 8.340 & 76.80 & 157.70 & 199.40 & 159.50 \\
$M_{2}[\mathrm{Nmm}]$ & -4170 & -3840 & -2523.4 & -199.40 & 2552.0 \\
$G_{\text {anal }}[\mathrm{N} / \mathrm{mm}]$ & 0.3917 & 0.3953 & 0.3944 & 0.3890 & 0.4035 \\
$G_{\text {CSDE }}[\mathrm{N} / \mathrm{mm}]$ & 0.3848 & 0.3883 & 0.3895 & 0.3872 & 0.3819 \\
$G[\mathrm{~N} / \mathrm{mm}][17]$ & 0.3969 & 0.3997 & 0.3963 & 0.3890 & 0.3862 \\
$\psi[\mathrm{deg}]$ & 54.40 & 33.90 & 4.04 & -30.90 & -72.20 \\
$\omega[\mathrm{deg}]$ & 58.22 & 57.74 & 57.05 & 56.36 & 55.86
\end{tabular}

\section{V. (B). Reinforced DCB-UBM Sandwich Specimen}

During fracture characterization tests of unreinforced sandwich specimens, excessive deformation of either crack flank will violate Linear Elastic Fracture Mechanics (LEFM). Reinforcing the fracture specimen with stiff doubler layers prevent excessive crack flank rotations (see Fig. 7). Moreover such layers will make it easier to attach loading tabs to specimens for experimental testing. The parameter $\omega$ is computed for a reinforced DCB-UBM sandwich specimen with a soft PVC foam core (H45). As earlier, aluminum face sheets were chosen $\left(h_{f}=2 \mathrm{~mm}\right)$. Steel reinforcement layers were chosen $\left(E_{s}=210 \mathrm{GPa}\right.$, $v_{\mathrm{r}}=0.3$ ) with a thickness $h_{r}=6 \mathrm{~mm}$ [15]. The total length of the specimen was $L=500 \mathrm{~mm}$ with a crack length, $a=200 \mathrm{~mm}$.

Results for the reinforced specimen are presented in Table 4. For the range of moment ratios examined, the phase angle $(\psi)$ varied from 18.74 to $77.31^{\circ}$, while the scalar parameter $\omega$, remained nearly constant with an average of $65.09^{\circ}( \pm 1.5 \%)$, see Table 4. An advantage of a $\omega$ parameter that is independent of loading, is that the mode-mixity phase angle may be computed using a single $\omega$ value. To further examine the parameter $\omega$, the phase angle $(\psi)$ was calculated for a range of MR using Eq. (31) with the average value of $\omega=65.09^{\circ}$ (Table 4). The results for $\psi$ in Table 4 show that $\psi$ values obtained using a fixed $\omega$ value $\left(\psi^{*}\right)$ closely match the ones from FEA.
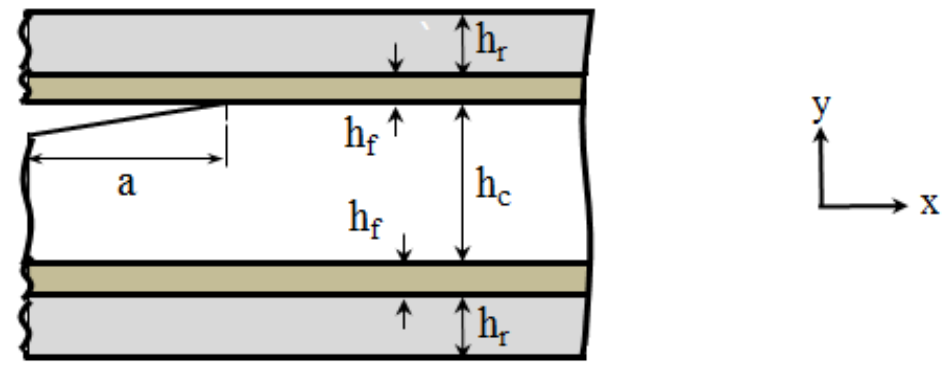

Figure 7. Sandwich DCB-UBM specimen reinforced with steel plates 
Table 4. G, $\psi$ and $\omega$ results for sandwich DCB-UBM specimen with PVC H45 foam core reinforced with steel layers

\begin{tabular}{l|lllll}
\hline Moment Ratio, $M R$ & -0.125 & -0.25 & -1.0 & 0.25 & 0.125 \\
$M_{1}[\mathrm{Nmm}]$ & 210 & 415 & 1110 & 410 & 210 \\
$M_{2}[\mathrm{Nmm}]$ & -1680 & -1660 & -1110 & 1640 & 1680 \\
$G_{\text {anal }}[\mathrm{J} / \mathrm{mm}]$ & 0.2254 & 0.1994 & 0.2005 & 0.2048 & 0.2049 \\
$G_{C S D E}[\mathrm{~J} / \mathrm{mm}]$ & 0.2075 & 0.2319 & 0.2078 & 0.2252 & 0.2248 \\
$\psi[$ deg] & 57.53 & 50.87 & 18.74 & 77.31 & 72.88 \\
$\omega[$ deg] Eq. (33) & 65.42 & 66.09 & 65.77 & 62.63 & 65.56 \\
$\psi^{*}$ [deg] Eq. (31) & 57.24 & 49.97 & 18.32 & 79.61 & 72.31
\end{tabular}

* calculated using $\omega$ (avg.) $=65.09^{\circ}$

\section{Influence of reinforcement layer thickness}

A study was conducted to examine the influence of reinforcement layer thickness on the $\omega$ parameter. A moderately dense H100 core with aluminum face sheet was considered. The face sheet and core thicknesses were held constant at $h_{f}=6 \mathrm{~mm}$ and $h_{c}=30 \mathrm{~mm}$ (see Table 1 for material properties). The thickness of the steel reinforcement doubler layers $\left(E_{r}=210 \mathrm{GPa}\right.$, $v_{\mathrm{r}}=0.3$ ) was varied from 1 to $6 \mathrm{~mm}$. The mode-mixity phase angle $\psi$, computed using CSDE method was used to obtain $\omega$ parameter using Eq. (33). The moment ratio (MR) was varied between -0.25 to 0.25 .

Results for the phase angle and $\omega$ parameter are provided in Table 5. For $h_{r}=1 \mathrm{~mm}$, the maximum deviation in $\omega$ is $\pm 1.7 \%$. Similar results are found for the other reinforcement thickness. This confirms that the results of $\omega$ for each reinforcement thickness concurred with the load-independent $\omega$ hypothesis. The results show, however, that $\omega$ depends on the thickness of the reinforcement layer. The difference between $\omega$ for thin $\left(64.19^{\circ}\right)$ and thick $\left(58.30^{\circ}\right)$ steel reinforcement layers is $10.1 \%$.

Average $\omega$ values obtained for each reinforcement thickness and MR values are listed in Table 5. These values are used to compute the phase angle $\psi$, here denoted $\psi^{*}$ from Eq. (31). Values of $\psi^{*}$ in Table 5 may be compared against the modemixity phase angle $(\psi)$ obtained using FEA. For most cases, $\psi^{*}$ agrees with $\psi$ obtained using FEA within 3\%. A maximum deviation of $9.2 \%$ is observed for MR $=0.0625$ and $h_{r}=6 \mathrm{~mm}$. 
Table 5. $\omega$ parameter for a $\mathbf{H 1 0 0}$ sandwich specimen with varying reinforcement thicknesses

\begin{tabular}{|c|c|c|c|c|c|}
\hline \multicolumn{6}{|c|}{ H100 core $(130 \mathrm{MPa}), h_{c}=30 \mathrm{~mm}, h_{f}=6 \mathrm{~mm}, h_{r}=1-6 \mathrm{~mm}$} \\
\hline Moment Ratio, MR & -0.250 & -0.0625 & -1 & 0.0625 & 0.250 \\
\hline $\mathbf{M}_{1}[\mathbf{N} . \mathbf{m m}]$ & 199 & 158 & 199 & 160 & 199 \\
\hline $\mathbf{M}_{2}[\mathbf{N} . \mathrm{mm}]$ & -798 & -2523 & -199 & 2550 & 798 \\
\hline \multicolumn{6}{|c|}{$h_{r}=1 \mathrm{~mm}$} \\
\hline Ganal $[\mathbf{J} / \mathbf{m m}]$ & 0.0881 & 0.7942 & 0.0140 & 0.8101 & 0.0872 \\
\hline$\psi[$ deg] & 45.2 & 60.0 & 9.97 & -112 & -97.4 \\
\hline \multirow[t]{2}{*}{$\omega[\operatorname{deg}]$} & 64.3 & 65.3 & 63.6 & 63.3 & 64.4 \\
\hline & & & & \multicolumn{2}{|c|}{$\omega_{1}(\mathrm{avg})=64.2$} \\
\hline $\boldsymbol{\psi} *[\mathrm{deg}]$ & 43.0 & 56.0 & 9.2 & -115 & -102 \\
\hline \multicolumn{6}{|c|}{$h_{r}=2 \mathrm{~mm}$} \\
\hline $\mathbf{G}_{\text {anal }}[\mathrm{J} / \mathrm{mm}]$ & 0.0672 & 0.6139 & 0.0099 & 0.6261 & 0.0665 \\
\hline$\psi[$ deg] & 45.0 & 58.8 & 10.6 & -114 & -100 \\
\hline$\omega[\operatorname{deg}]$ & 62.9 & 63.8 & 62.3 & 61.9 & 62.8 \\
\hline & & & & \multicolumn{2}{|c|}{$\omega_{2}(\operatorname{avg})=62.7$} \\
\hline$\psi *[\operatorname{deg}]$ & 44.0 & 56.2 & 11.0 & -115 & -103 \\
\hline \multicolumn{6}{|c|}{$h_{r}=3 \mathrm{~mm}$} \\
\hline $\mathrm{G}_{\text {anal }}[\mathrm{J} / \mathrm{mm}]$ & 0.0518 & 0.4769 & 0.0072 & 0.4862 & 0.0512 \\
\hline$\psi[\operatorname{deg}]$ & 44.4 & 57.5 & 10.7 & -116 & -103 \\
\hline$\omega[\mathrm{deg}]$ & 61.6 & 62.4 & 61.0 & 60.6 & 61.4 \\
\hline & & & & \multicolumn{2}{|c|}{$\omega_{3}(\operatorname{avg})=61.4$} \\
\hline$\psi *[$ deg] & 44.6 & 56.4 & 12.0 & -116 & -104 \\
\hline \multicolumn{6}{|c|}{$h_{r}=4 \mathrm{~mm}$} \\
\hline Ganal $[\mathbf{J} / \mathbf{m m}]$ & 0.0404 & 0.3736 & 0.0055 & 0.3809 & 0.0399 \\
\hline$\psi[$ deg] & 43.7 & 56.3 & 10.6 & -117 & -104 \\
\hline$\omega[\mathrm{deg}]$ & 60.3 & 61.1 & 59.9 & 59.4 & 60.2 \\
\hline & & & & \multicolumn{2}{|c|}{$\omega_{4}($ avg $)=60.2$} \\
\hline$\psi *[\operatorname{deg}]$ & 44.6 & 56.4 & 12.0 & -116 & -104 \\
\hline \multicolumn{6}{|c|}{$h_{r}=5 \mathrm{~mm}$} \\
\hline Ganal $[\mathrm{J} / \mathrm{mm}]$ & 0.0319 & 0.2959 & 0.0042 & 0.3015 & 0.0314 \\
\hline$\psi[\mathrm{deg}]$ & 42.9 & 55.1 & 10.2 & -127.9 & -106.0 \\
\hline$\omega[\operatorname{deg}]$ & 59.2 & 59.9 & 58.8 & 56.8 & 59.0 \\
\hline & & & & \multicolumn{2}{|c|}{$\omega_{5}($ avg $)=58.8$} \\
\hline$\psi^{*}[\operatorname{deg}]$ & 45.0 & 56.5 & 12.8 & -116 & -104 \\
\hline \multicolumn{6}{|c|}{$h_{r}=6 \mathrm{~mm}$} \\
\hline $\mathrm{G}_{\text {anal }}[\mathrm{J} / \mathrm{mm}]$ & 0.0255 & 0.2370 & 0.0033 & 0.2414 & 0.0251 \\
\hline$\psi[\mathrm{deg}]$ & 42.0 & 54.0 & 9.84 & -127 & -108 \\
\hline$\omega[\mathrm{deg}]$ & 58.1 & 58.8 & 57.9 & 58.8 & 58.0 \\
\hline & & & & \multicolumn{2}{|c|}{$\omega_{6}(\operatorname{avg})=58.3$} \\
\hline$\psi^{*}[\operatorname{deg}]$ & 43.2 & 56.5 & 13.3 & -116 & -104 \\
\hline
\end{tabular}

*Phase angle $(\psi)$ computed with an average $\omega=60.92^{\circ}$ using Eq. (31) 


\section{VI. (A). Parametric study on influence of reinforcement layer thickness $\left(h_{r}\right)$}

In order to further examine the dependence of the $\omega$ parameter on the reinforcement layer thickness, the study is extended to other foam core sandwich configurations: E-glass/H45, E-glass/H100, E-glass/H250, Al/H45 and Al/H250. The E-glass face laminates considered are quasi-isotropic (see Table 1 for material properties). Face thicknesses of 6 and 2 mm were considered for the glass fiber and aluminum faces. As before, the steel reinforcement layer $\left(E_{r}=210 \mathrm{GPa}, v_{\mathrm{r}}=0.3\right)$ thickness is varied from 1 to $6 \mathrm{~mm}$. The $\omega$ parameter is calculated from Eq. (33). An average from two MR values (MR $=-0.250$ and +0.250$)$ was used to determine $\omega$.

Fig. 8 shows a plot of $\omega$ vs thickness of the steel reinforcement layer. It is noticed that when stiff aluminum face sheets are combined with a soft core (H45), the omega variation across the range of reinforcement layer thicknesses, is $9 \%$. However, for stiffer cores the variation is below 5\%. For sandwich specimens with E-glass face sheets and H45 core, a deviation of 7.2\% in $\omega$ across $h_{r}$ is observed. The deviation in $\omega$ across $h_{r}$ for sandwich specimens with E-glass face sheets and stiffer H250 core is below $2.8 \%$. The trends in $\omega$ vs $h_{r}$ are quantified using a polynomial curve fit to the data. The curve fitting parameters are provided in Table 6.

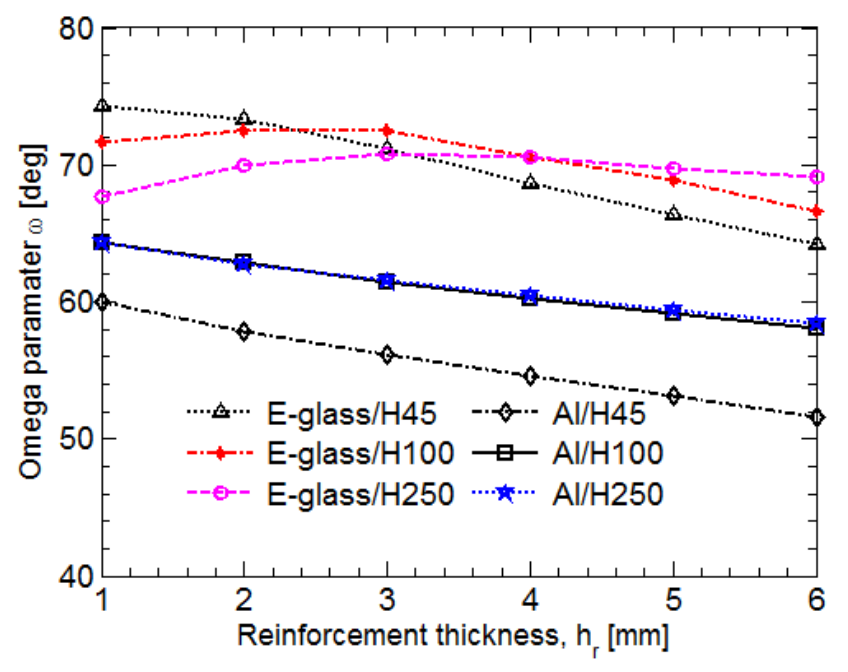

Figure 8. Omega parameter variation for typical sandwich specimens across reinforcement thickness 
Table 6. Curve fitting parameters for $\omega$ vs $h_{r}$ plot for E-glass/PVC core and aluminum/PVC core sandwich systems

\begin{tabular}{|l|l|}
\hline \multicolumn{2}{|l|}{ Aluminum/PVC Core, $\omega=\varsigma_{1} h_{s}+\varsigma_{2}$} \\
\hline $\mathrm{Al} / \mathrm{H} 45$ & $\varsigma_{1}=-1.649, \varsigma_{2}=61.33$ \\
$\mathrm{Al} / \mathrm{H} 100$ & $\varsigma_{1}=-1.252, \varsigma_{2}=65.40$ \\
\hline $\mathrm{Al} / \mathrm{H} 250$ & $\varsigma_{1}=-1.158, \varsigma_{2}=65.22$ \\
\hline E-glass/PVC Core, $\omega=\eta_{1} h_{s}^{2}+\eta_{2} h_{s}+\eta_{3}$ \\
\hline E-glass/H45 & $\eta_{1}=-0.111, \eta_{2}=1.34, \eta_{3}=76.1$ \\
\hline E-glass/H100 & $\eta_{1}=-0.401, \eta_{2}=1.71, \eta_{3}=70.5$ \\
\hline E-glass/H250 & $\eta_{1}=-0.389, \eta_{2}=2.90, \eta_{3}=65.4$ \\
\hline
\end{tabular}

\section{Conclusion}

Closed form expressions for energy release rate and mode-mixity phase angle for a reinforced DCB-UBM sandwich specimen were derived using a superposition scheme, the $J$-integral and laminate beam theory. The phase angle was expressed in terms of a load independent scalar parameter $\omega$. Finite-element analysis was used to determine energy release rate and mode-mixity phase angle for the various sandwich systems analysed. It was found that the $\omega$ value remained practically independent of the loading configuration for a fixed reinforcement thickness. The value of $\omega$ varies weakly with reinforcement thickness and the dependence is expressed by curve fitting for typical sandwich specimens. The closed form expressions derived in this paper can be used for fracture analysis of various sandwich systems with thin face sheets requiring reinforcement layers.

\section{APPENDIX A. J-integral calculations}

Each beam (\#1 and \#2) is analyzed separately, Figs. A1 and A2. The J integral is calculated from the stress $\sigma_{x}$ in each layer along the paths: $\Gamma_{1}-\Gamma_{3}$ and $\Gamma_{3}-\Gamma_{10}$, see Fig. 5 . The stress, $\sigma_{\mathrm{x}}$, in each layer due to moment and force was calculated and substituted in Eq. (15). All equations are expressed in terms of the elastic modulus for ply $k$ in the $x$-direction, $\bar{E}_{k}$. As explained in section II, for plane strain, $\bar{E}_{k}=E_{k} /\left(1-v_{k}^{2}\right)$ while for plane stress, $\bar{E}_{k}=E_{k}$. 


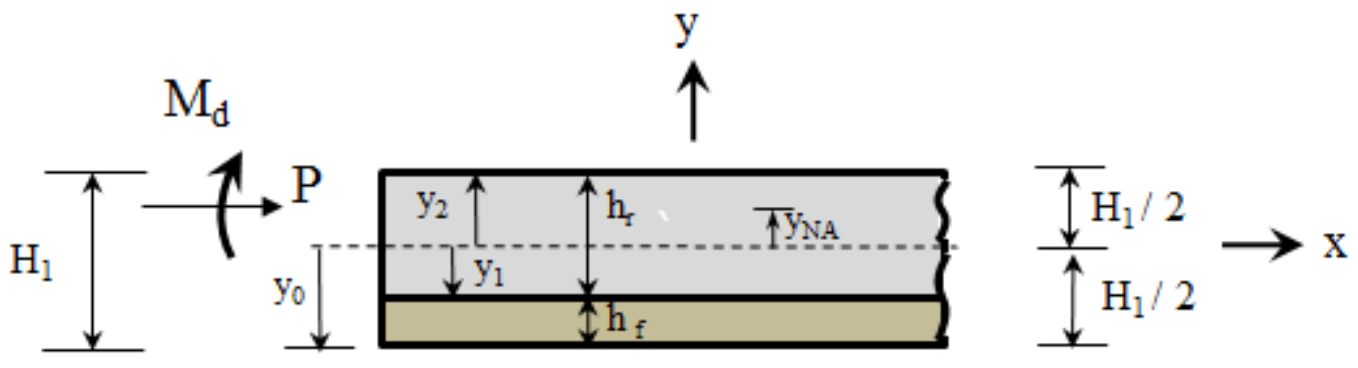

Figure A1. Force and moment acting on beam \#1

Figure A1 shows the beam consisting of upper face sheet and stiffener layer acted upon by a force and moment according to the superposition analysis. The force $P$, and moment $M_{d}$ act on the neutral axis (see Fig. A1). The location of the neutral axis is given by the ratio of extension-bending coupling stiffness and extensional stiffness ( $y_{N A}=B / A$ ). The stress $\sigma_{x}$ in each layer is expressed as follows:

$$
\sigma_{x}=\left\{\begin{array}{l}
\frac{-P \bar{E}_{r}}{(\bar{E} h)_{d}}+\frac{-M_{d} \bar{E}_{r}}{\left(D_{d}-B_{d}^{2} / A_{d}\right)}\left(y-y_{N A}\right) ; y_{1} \leq y \leq y_{2} \text { [Reinforcement] } \\
\frac{-P \bar{E}_{f}}{(\bar{E} h)_{d}}+\frac{-M_{d} \bar{E}_{f}}{\left(D_{d}-B_{d}^{2} / A_{d}\right)}\left(y-y_{N A}\right) ; y_{0} \leq y \leq y_{1} \text { [UpperFacesheet] }
\end{array}\right.
$$

where $(\bar{E} h)_{d}=\bar{E}_{r} h_{r}+\bar{E}_{f} h_{f}$. The $J$-integral is calculated for debonded beam by substituting Eqs. (A1) in Eq. (15) along paths ( $\Gamma_{9}$ and $\left.\Gamma_{10}\right)$ to obtain:

$$
\begin{aligned}
J_{\Gamma 9} & =\frac{1}{2 \bar{E}_{r}} \int_{y_{1}}^{y_{2}}\left(\frac{-P \bar{E}_{r}}{(\bar{E} h)_{d}}-\frac{M_{d} \bar{E}_{r}}{H_{d}}\left(y-e_{d}\right)\right)^{2} \cdot d y \\
& =\frac{P^{2} \bar{E}_{r} h_{r}}{2(\bar{E} h)_{d}^{2}}+\frac{M_{d}^{2} \bar{E}_{r}}{2 H_{d}^{2}}\left[\frac{h_{r}}{3}\left(\frac{3 h_{f}^{2}}{4}+\frac{h_{r}^{2}}{4}\right)-e_{d} h_{f} h_{r}+e_{d}^{2} h_{r}\right]-\frac{P M_{d} \bar{E}_{r}}{(\bar{E} h)_{d} H_{d}}\left[\frac{h_{f} h_{r}}{2}-e_{d} h_{r}\right]
\end{aligned}
$$




$$
\begin{aligned}
J_{\Gamma 10} & =\frac{1}{2 \bar{E}_{f}} \int_{y_{0}}^{y_{1}}\left(\frac{-P \bar{E}_{f}}{(\bar{E} h)_{d}}+\frac{M_{d} \bar{E}_{f}}{H_{d}}\left(y-e_{d}\right)\right)^{2} \cdot d y \\
& =\frac{P^{2} \bar{E}_{f} h_{f}}{2(\bar{E} h)_{d}^{2}}+\frac{M_{d}^{2} \bar{E}_{f}}{2 H_{d}^{2}}\left[\frac{h_{f}}{3}\left(\frac{h_{f}^{2}}{4}+\frac{3 h_{r}^{2}}{4}\right)+e_{d} h_{f} h_{r}+e_{d}^{2} h_{f}\right]-\frac{P M_{d} \bar{E}_{f}}{(\bar{E} h)_{d} H_{d}}\left[\frac{-h_{f} h_{r}}{2}-e_{d} h_{f}\right]
\end{aligned}
$$

where $H_{d}=\left(D_{d}-B_{d}^{2} / A_{d}\right)$ and $e_{d}=y_{N A}$ (neutral axis in Fig. A1).

The J-integral contribution from the debonded beam becomes:

$$
\begin{gathered}
J_{\text {Debonded }}=J_{\Gamma 9}+J_{\Gamma 10} \\
J_{\text {Debonded }}=\frac{P^{2}}{(\bar{E} h)_{d}^{2}} L_{1}+\frac{M_{d}^{2}}{H_{d}^{2}} L_{2}+\frac{P M_{d}}{(\bar{E} h)_{d} H_{d}} L_{3}
\end{gathered}
$$

where

$$
\begin{gathered}
L_{1}=\frac{1}{2}\left(\bar{E}_{r} h_{r}+\bar{E}_{f} h_{f}\right) \\
L_{2}=\frac{\bar{E}_{r}}{2}\left[\frac{h_{r}}{3}\left(\frac{3}{4} h_{f}^{2}+\frac{1}{4} h_{r}^{2}\right)-e_{d} h_{f} h_{r}+e_{d}^{2} h_{r}\right]+\frac{\bar{E}_{f}}{2}\left[\frac{h_{f}}{3}\left(\frac{1}{4} h_{f}^{2}+\frac{3}{4} h_{r}^{2}\right)+e_{d} h_{f} h_{r}+e_{d}^{2} h_{f}\right] \\
L_{3}=\bar{E}_{r}\left[\frac{h_{f} h_{r}}{2}-e_{d} h_{r}\right]-\bar{E}_{f}\left[\frac{h_{f} h_{r}}{2}+e_{d} h_{f}\right]
\end{gathered}
$$




\section{Substrate beam (Beam \#2):}

Analysis similar to the one above for the debonded beam is conducted here. The layers of the substrate beam are the lower reinforcement layer, bottom face sheet and core (see Fig. 10). J is evaluated along paths $\left(\Gamma_{1}-\Gamma_{3}\right)$ in Fig. 5 . The stress $\sigma_{\mathrm{x}}$ due to $P$ and $M^{*}$ (Fig. A2) can be expressed as:

$$
\sigma_{x}=\left\{\begin{array}{l}
\left.\frac{P \bar{E}_{c}}{(\bar{E} h)_{s}}-\frac{M^{*} \bar{E}_{c}}{\left(D_{s}-B_{s}^{2} / A_{s}\right)}\left(y-y_{N A}\right) ; y_{2} \leq y \leq y_{3} \quad \text { [Core }\right] \\
\left.\frac{P \bar{E}_{f}}{(\bar{E} h)_{s}}-\frac{M^{*} \bar{E}_{f}}{\left(D_{s}-B_{s}^{2} / A_{s}\right)}\left(y-y_{N A}\right) ; y_{1} \leq y \leq y_{2} \quad \text { [LowerFacesheet }\right] \\
\frac{P \bar{E}_{r}}{(\bar{E} h)_{s}}-\frac{M^{*} \bar{E}_{r}}{\left(D_{s}-\frac{B_{s}^{2} / A_{s}}{A_{s}}\right)}\left(y-y_{N A}\right) ; y_{0} \leq y \leq y_{1} \quad \text { [Reinforcment] }
\end{array}\right.
$$

where $(\bar{E} h)_{s}=\bar{E}_{r} h_{r}+\bar{E}_{f} h_{f}+\bar{E}_{c} h_{c}$. The location of neutral axis $\left(y_{N A}=B / A\right)$ for the substrate beam (\#2) is shown in Fig. A2.

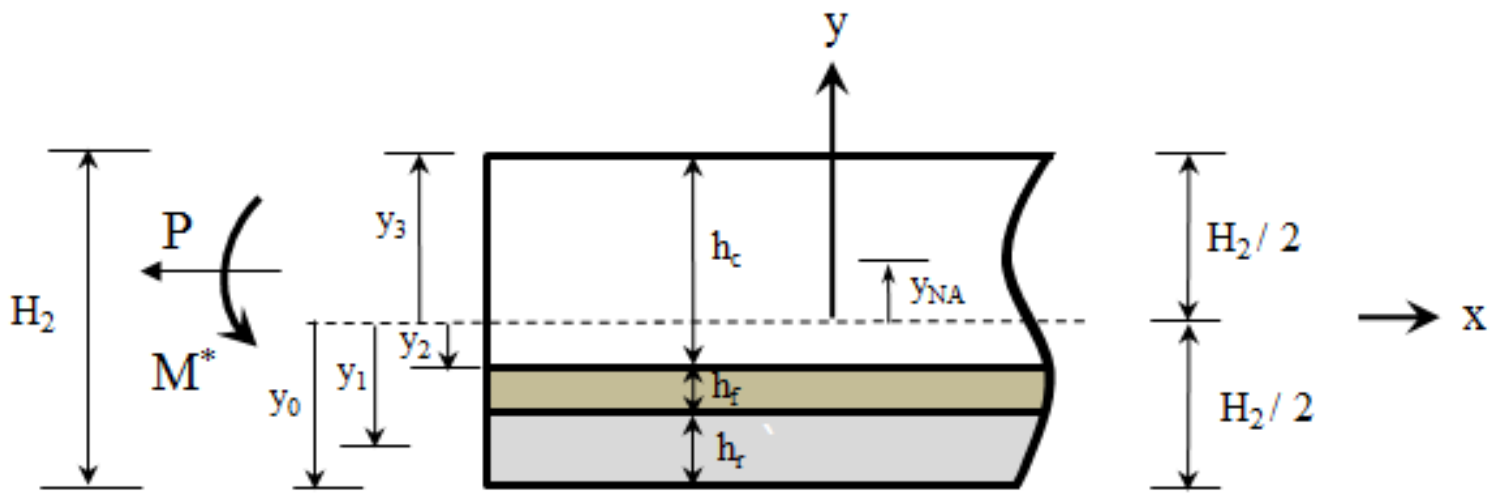

Figure A2. Loads acting on substrate beam \#2

Substituting Eqs. (A6) in (15) for each path $\left(\Gamma_{1}-\Gamma_{3}\right)$ :

$$
\begin{aligned}
J_{\Gamma 1} & =\frac{1}{2 \bar{E}_{c}} \int_{y_{2}}^{y_{3}}\left(\frac{P \bar{E}_{c}}{(\bar{E} h)_{s}}-\frac{M^{*} \bar{E}_{c}}{H_{s}}\left(y-e_{s}\right)\right)^{2} . d y \\
& =\frac{P^{2} \bar{E}_{c} h_{c}}{2(\bar{E} h)_{s}^{2}}+\frac{M^{* 2} \bar{E}_{c}}{2 H_{s}^{2}}\left[\frac{h_{c}}{3}\left(\frac{3 h_{r}^{2}}{4}+\frac{3 h_{r} h_{f}}{2}+\frac{h_{c}^{2}}{4}+\frac{3 h_{f}^{2}}{4}\right)-e_{s} h_{c}\left(h_{f}+h_{r}\right)+e_{s}^{2} h_{c}\right]-\frac{P M^{*} \bar{E}_{c}}{(\bar{E} h)_{s} H_{s}}\left[\frac{h_{c}\left(h_{f}+h_{r}\right)}{2}-e_{s} h_{r}\right]
\end{aligned}
$$




$$
\begin{aligned}
J_{\Gamma 2} & =\frac{1}{2 \bar{E}_{f}} \int_{y_{1}}^{y_{2}}\left(\frac{P \bar{E}_{f}}{(E h)_{s}}-\frac{M^{*} \bar{E}_{f}}{H_{s}}\left(y-e_{s}\right)\right)^{2} \cdot d y \\
& =\frac{P^{2} \bar{E}_{f} h_{f}}{2(\bar{E} h)_{s}^{2}}+\frac{M^{* 2} \bar{E}_{f}}{2 H_{s}^{2}}\left[\frac{h_{f}}{3}\left(\frac{3 h_{r}^{2}}{4}-\frac{3 h_{r} h_{c}}{2}+\frac{3 h_{c}^{2}}{4}+\frac{h_{f}^{2}}{4}\right)-e_{s} h_{f}\left(h_{r}-h_{c}\right)+e_{s}^{2} h_{f}\right]-\frac{P M^{*} \bar{E}_{f}}{(\bar{E} h)_{s} H_{s}}\left[\frac{h_{f}\left(h_{r}-h_{c}\right)}{2}-e_{s} h_{f}\right] \\
J_{\Gamma 3} & =\frac{1}{2 \bar{E}_{r}} \int_{y_{0}}^{y 1}\left(\frac{P \bar{E}_{r}}{(\bar{E} h)_{s}}-\frac{M^{*} \bar{E}_{r}}{H_{s}}\left(y-e_{s}\right)\right)^{2} \cdot d y \\
= & \frac{P^{2} \bar{E}_{r} h_{r}}{2(\bar{E} h)_{s}^{2}}+\frac{M^{* 2} \bar{E}_{r}}{2 H_{s}^{2}}\left[\frac{h_{r}}{3}\left(\frac{h_{r}^{2}}{4}+\frac{3 h_{c}^{2}}{4}+\frac{3}{2} h_{c} h_{f}+\frac{3 h_{f}^{2}}{4}\right)+e_{s} h_{r}\left(h_{c}+h_{f}\right)+e_{s}^{2} h_{r}\right]-\frac{P M^{*} \bar{E}_{r}}{(\bar{E} h)_{s} H_{s}}\left[\frac{h_{r}\left(-h_{c}-h_{f}\right)}{2}-e_{s} h_{r}\right]
\end{aligned}
$$

$\mathrm{J}$ for the substrate beam is obtained by summation of contributions from the individual layers:

$$
J_{\text {Substrate }}=J_{\Gamma 1}+J_{\Gamma 2}+J_{Г 3}
$$

Substitution yields:

$$
J_{\text {Substrate }}=\frac{P^{2}}{(\bar{E} h)_{s}^{2}} V_{1}+\frac{M^{* 2}}{H_{s}^{2}} V_{2}-\frac{P M^{*}}{(\bar{E} h)_{s} H_{s}} V_{3}
$$

where

$$
\begin{gathered}
V_{1}=\frac{1}{2}\left(\bar{E}_{c} h_{c}+\bar{E}_{f} h_{f}+\bar{E}_{r} h_{r}\right) \\
V_{2}=\frac{\bar{E}_{c}}{2}\left[\frac{h_{c}}{3}\left(\frac{3}{4} h_{r}^{2}+1.5 h_{r} h_{f}+\frac{3}{4} h_{f}^{2}+\frac{1}{4} h_{c}^{2}\right)-e_{s} h_{c}\left(h_{f}+h_{r}\right)+e_{s}^{2} h_{c}\right]+ \\
\frac{\bar{E}_{f}}{2}\left[\frac{h_{f}}{3}\left(\frac{3}{4} h_{r}^{2}-1.5 h_{r} h_{c}+\frac{1}{4} h_{f}^{2}+\frac{3}{4} h_{c}^{2}\right)-e_{s} h_{f}\left(h_{r}-h_{c}\right)+e_{s}^{2} h_{f}\right]+ \\
\frac{\bar{E}_{r}}{2}\left[\frac{h_{r}}{3}\left(\frac{1}{4} h_{r}^{2}+1.5 h_{f} h_{c}+\frac{3}{4} h_{f}^{2}+\frac{3}{4} h_{c}^{2}\right)+e_{s} h_{r}\left(h_{c}+h_{f}\right)+e_{s}^{2} h_{r}\right] \\
V_{3}=\bar{E}_{c}\left[\frac{h_{c}\left(h_{f}+h_{r}\right)}{2}-e_{s} h_{c}\right]+\bar{E}_{f}\left[\frac{h_{f}\left(h_{r}-h_{c}\right)}{2}-e_{s} h_{f}\right]+\bar{E}_{r}\left[\frac{h_{r}\left(-h_{c}-h_{f}\right)}{2}-e_{s} h_{r}\right]
\end{gathered}
$$


where $H_{s}=\left(D_{s}-\frac{B_{s}^{2}}{A_{s}}\right) ; e_{s}=y_{N A}$ (neutral axis in Fig. A2).

Now, $M^{*}$ can be expressed in terms of $M_{d}$ as, $M^{*}=M_{d}+P \Delta_{1}$ (see Eq. (2)). Substitution for $M^{*}$ in Eq. (A9) yields,

$$
\begin{aligned}
J_{\text {Substrate }} & =\frac{P^{2}}{(\bar{E} h)_{s}^{2}} V_{1}+\frac{\left(M_{d}+P \Delta_{1}\right)^{2}}{H_{s}^{2}} V_{2}+\frac{P\left(M_{d}+P \Delta_{1}\right)}{(\bar{E} h)_{s} H_{s}} V_{3} \\
& =\frac{P^{2}}{(\bar{E} h)_{s}^{2}} V_{1}+\frac{M_{d}^{2}}{H_{s}^{2}} V_{2}+\frac{P^{2} \Delta_{1}^{2}}{H_{s}^{2}} V_{2}+\frac{2 M_{d} P \Delta_{1}}{H_{s}^{2}} V_{2}+\frac{M_{d} P \Delta_{1}}{(\bar{E} h)_{s} H_{s}} V_{3}-\frac{P^{2} \Delta_{1}^{2}}{(\bar{E} h)_{s} H_{s}} V_{3}
\end{aligned}
$$

The $J$ integral for both substrate and debonded beams are summed to obtain the total $J$ as:

$$
J=G=J_{\text {Debonded }}+J_{\text {Substrate }}=J_{1}+J_{2}+J_{3}+J_{9}+J_{10}
$$

Substituting Eqs. (A4) and (A11) in (A12):

$$
\begin{aligned}
G= & P^{2}\left(\frac{L_{1}}{(\bar{E} h)_{d}^{2}}+\frac{V_{1}}{(\bar{E} h)_{s}^{2}}+\frac{V_{2} \Delta_{1}^{2}}{H_{s}^{2}}-\frac{V_{3} \Delta_{1}}{(\bar{E} h)_{s} H_{s}}\right)+M_{d}^{2}\left(\frac{L_{2}}{H_{d}^{2}}+\frac{V_{2}}{H_{s}^{2}}\right)+ \\
& M_{d} P\left(\frac{2 V_{2} \Delta_{1}}{H_{s}^{2}}-\frac{L_{3}}{(\bar{E} h)_{d} H_{d}}-\frac{V_{3}}{(\bar{E} h)_{s} H_{s}}\right)
\end{aligned}
$$

\section{Appendix B. Homogenization of laminate face sheet}

Several sandwich panels employ multi-directional composite laminates, Fig. B1. The analysis presented here assumes isotropic constituent where $E_{f}$ refers to Young's modulus of an isotropic material. To use the analysis presented here for sandwich specimens with composite laminate face sheets, a homogenized modulus should be appropriate. 


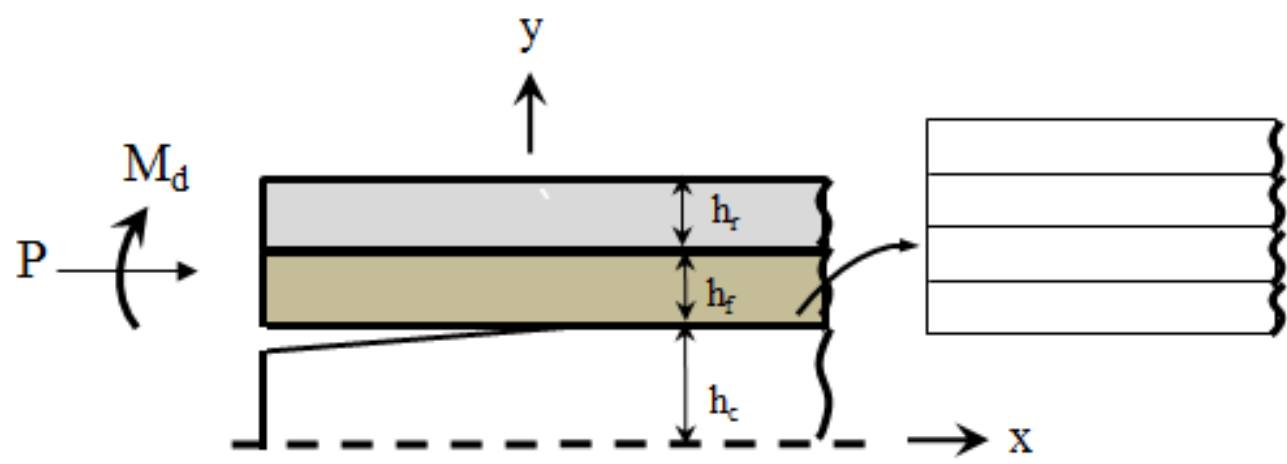

Figure B1. Schematic of typical face laminate.

The homogenized modulus may be computed using laminated plate theory [26]. For an element of a laminate, the stress resultants may be expressed as:

$$
\left\{\begin{array}{l}
N \\
M
\end{array}\right\}=\left[\begin{array}{ll}
A & B \\
B & D
\end{array}\right]\left\{\begin{array}{l}
\varepsilon^{0} \\
\kappa
\end{array}\right\}
$$

where $\varepsilon^{0}$ are the mid-surface strains and $\kappa$ are the mid-surface curvatures. $A, B$ and $D$ represent the extensional, coupling and bending stiffness matrices of the laminate. It should be noted that symmetrical laminates are considered for this evaluation, hence $B=0$. The 6 x 6 matrix in Eq. (B1) may be inverted to obtain the compliance matrix:

$$
\left[\begin{array}{c}
\varepsilon_{x}^{0} \\
\varepsilon_{y}^{0} \\
\gamma_{x y}^{0} \\
\kappa_{x} \\
\kappa_{y} \\
\kappa_{x y}
\end{array}\right]=\left[\begin{array}{cccccc}
a_{11} & a_{12} & a_{16} & 0 & 0 & 0 \\
a_{12} & a_{22} & a_{26} & 0 & 0 & 0 \\
a_{16} & a_{26} & a_{66} & 0 & 0 & 0 \\
0 & 0 & 0 & d_{11} & d_{12} & d_{16} \\
0 & 0 & 0 & d_{12} & d_{22} & d_{26} \\
0 & 0 & 0 & d_{16} & d_{26} & d_{66}
\end{array}\right]\left[\begin{array}{c}
N_{x} \\
N_{y} \\
N_{x y} \\
M_{x} \\
M_{y} \\
M_{x y}
\end{array}\right]
$$

By subjecting the laminate strip to an axial load $N_{x}$ only, the extension strain becomes:

$$
\varepsilon_{x}^{0}=a_{11} N_{x}
$$

The effective extensional stiffness can be written as: 


$$
E_{x}^{\mathrm{e}}=\frac{\sigma_{x}}{\varepsilon_{x}^{0}}=\frac{N_{x}}{h a_{11} N_{x}}=\frac{1}{h a_{11}}
$$

Similarly, by applying only moment about the $x$-axis, the curvature can be expressed in terms of moment, $M$ as:

$$
\kappa_{x}=\frac{M}{E_{x}^{f}}=M_{x} d_{11}
$$

With $I=w h^{3} / 12$ and $M_{x}=M / w$, this analysis provides the effective flexural modulus:

$$
E_{x}^{f}=\frac{12}{d_{11} h^{3}}
$$

The average value of $E_{x}^{\mathrm{e}}$ and $E_{x}^{f}$ may be used to replace $E$ in the analysis.

\section{Acknowledgments}

The financial support from the Danish Centre for Composite Structures and Materials (DCCSM) funded by the Danish Innovation Foundation (Grant: 09-067212) is gratefully acknowledged. Furthermore, the financial support of Otto Mønsted Foundation (Grant: 16-70-0970) to the first author for his visit to Florida Atlantic University is gratefully acknowledged. The third author received support from the National Institute of Aerospace (NIA) and the Office of Naval Research, US Navy (ONR). The NIA and ONR program managers, Dr. Ronald Krueger, and Dr. Yapa Rajapakse showed keen interest in this project and are gratefully acknowledged.

\section{References}

[1] L. A. Carlsson, L. S. Sendlein, and S. L. Merry, "Characterization of Face Sheet/Core Shear Fracture of Composite Sandwich Beams,” J. Compos. Mater., vol. 25, no. 1, pp. 101-116, 1991. 
investigation,” Eng. Fract. Mech., vol. 47, no. 6, pp. 825-841, 1994.

[3] X. Li and L. A. Carlsson, "The Tilted Sandwich Debond (TSD) Specimen for Face/Core Interface Fracture Characterization,” J. Sandw. Struct. Mater., vol. 1, no. 1, pp. 60-75, 1999.

[4] J. Ratcliffe and W. J. Cantwell, "Center Notch Flexure Sandwich Geometry for Characterizing Skin-Core Adhesion in Thin-Skinned Sandwich Structures,” J. Reinf. Plast. Compos., vol. 20, no. 11, pp. 945-970, 2001.

[5] A. Quispitupa, C. Berggreen, and L. A. Carlsson, "On the analysis of a mixed mode bending sandwich specimen for debond fracture characterization,” Eng. Fract. Mech., vol. 76, no. 4, pp. 594-613, 2009.

[6] W. J. Cantwell, G. Broster, and P. Davies, "The Influence of Water Immersion on Skin-Core Debonding in GFRPBalsa Sandwich Structures,” J. Reinf. Plast. Compos., vol. 15, no. 11, pp. 1161-1172, 1996.

[7] J. R. Reeder and J. R. Crews, “Mixed-mode bending method for delamination testing,” AIAA J., vol. 28, no. 7, pp. 1270-1276, 1990.

[8] ASTM International, “ASTM D6671/D6671M-13e1, Standard Test Method for Mixed Mode I-Mode II Interlaminar Fracture Toughness of Unidirectional Fiber Reinforced Polymer Matrix Composites,” West Conshohocken, PA, 2013.

[9] A. Quispitupa, C. Berggreen, and L. A. Carlsson, "Design Analysis of the Mixed Mode Bending Sandwich Specimen,” J. Sandw. Struct. Mater., vol. 12, no. 2, pp. 253-272, 2010.

[10] M. Rinker, J. G. Ratcliffe, D. O. Adams, and R. Krueger, “Characterizing Facesheet/Core Disbonding in Honeycomb Core Sandwich Structure,” NASA Technical Publication TP-2013-21. 2013.

[11] J. G. Ratcliffe and J. R. Reeder, "Sizing a single cantilever beam specimen for characterizing facesheet-core debonding in sandwich structure,” J. Compos. Mater., vol. 45, no. 25, pp. 2669-2684, 2011.

[12] J. Ratcliffe and R. Krueger, "Face Sheet/Core Disbonding in Sandwich Composite Components: A Road Map to Standardization: Test Method Development," in 11th International Conference on Sandwich Structures, Dania Beach, FL, 20 - 22 May 2016. 
[13] B. F. Sørensen, K. Jørgensen, T. K. Jacobsen, and R. C. Østergaard, “DCB-specimen loaded with uneven bending moments,” Int. J. Fract., vol. 141, no. 1-2, pp. 163-176, 2006.

[14] R. C. Østergaard, B. F. Sørensen, and P. Brøndsted, "Measurement of Interface Fracture Toughness of Sandwich Structures under Mixed Mode Loadings,” J. Sandw. Struct. Mater., vol. 9, no. 5, pp. 445-466, 2007.

[15] C. Lundsgaard-Larsen, B. F. Sørensen, C. Berggreen, and R. C. Østergaard, “A modified DCB sandwich specimen for measuring mixed-mode cohesive laws,” Eng. Fract. Mech., vol. 75, no. 8, pp. 2514-2530, 2008.

[16] Z. Suo and J. W. Hutchinson, “Interface crack between two elastic layers,” Int. J. Fract., vol. 43, no. 1, pp. 1-18, 1990.

[17] G. A. Kardomateas, C. Berggreen, and L. A. Carlsson, “Energy-Release Rate and Mode Mixity of Face/Core Debonds in Sandwich Beams,” AIAA J., vol. 51, no. 4, pp. 885-892, 2013.

[18] Z. Suo and J. W. Hutchinson, “Interface crack between two elastic layers,” Int. J. Fract., vol. 43, pp. 1-18, 1990.

[19] L. A. Carlsson, R. C. Matteson, F. Aviles, and D. C. Loup, "Crack path in foam cored DCB sandwich fracture specimens,” Compos. Sci. Technol., vol. 65, no. 15, pp. 2612-2621, 2005.

[20] J. R. Rice, “A Path Independent Integral and the Approximate Analysis of Strain Concentration by Notches and Cracks,” J. Appl. Mech., vol. 35, no. 2, p. 379, 1968.

[21] J. W. Hutchinson, M. E. Mear, and J. R. Rice, “Crack Paralleling an Interface Between Dissimilar Materials,” J. Appl. Mech., vol. 54, no. 4, 1987.

[22] J. W. Hutchinson and Z. Suo, “Mixed Mode Cracking in Layered Materials,” Adv. Appl. Mech., vol. 29, pp. 63-191, 1991.

[23] M. D. Thouless, A. G. Evans, M. F. Ashby, and J. W. Hutchinson, “The edge cracking and spalling of brittle plates,” Acta Metall., vol. 35, no. 6, pp. 1333-1341, 1987.

[24] C. Berggreen, B. C. Simonsen, and K. K. Borum, “Experimental and Numerical Study of Interface Crack Propagation 
in Foam-cored Sandwich Beams,” J. Compos. Mater., vol. 41, no. 4, pp. 493-520, 2006.

[25] “ANSYS Mechanical User’s Guide.” ANSYS, Inc., Southpointe, PA, 2015.

[26] L. A. Carlsson, D. F. Adams, and R. B. Pipes, Experimental characterization of advanced composite materials. Boca Raton: CRC press, 2014. 